\title{
Comparison of Potassium and Sodium Content in Diet and Non-Diet Soft Drinks by Using Capillary Electrophoresis with Capacitively Coupled Contactless Conductivity Detection
}

\author{
Ivanilce Cristina Guimarães, José Alberto Fracassi da Silva, and Dosil Pereira de Jesus* \\ Institute of Chemistry, University of Campinas - UNICAMP, 13083-970, Campinas, SP, Brazil. \\ Instituto Nacional de Ciência e Tecnologia em Bioanalitica, Campinas, SP, Brazil. \\ *Corresponding Author: Prof. Dr. Dosil Pereira de Jesus - Grupo de Eletroforese e Microssistemas de Análise \\ Instituto de Química, Universidade Estadual de Campinas - P.O. Box 6154, 13083-970 Campinas, SP, Brazil \\ Fax: +55 (19) 3521-3023 - E-mail:dosil@iqm.unicamp.br
}

\begin{abstract}
Capillary electrophoresis (CE) with capacitively coupled contactless conductivity detection $\left(C^{4} \mathrm{D}\right)$ was used for determination of sodium and potassium concentrations in diet and non-diet soft drinks. Higher sodium concentrations were found in the diet samples due to the utilization of sodium salts of cyclamate and saccharine as sweeteners. The CE-C $\mathrm{C}^{4} \mathrm{D}$ method can be used by food industries and health regulatory agencies for monitoring sodium and potassium content, not only in soft drink but in many others food products.
\end{abstract}

Keywords: capillary electrophoresis, capacitively coupled contactless conductivity detection, soft drinks, sodium, potassium

\section{Introduction}

Sodium and potassium concentrations in foods are important nutritional information especially for people suffering from arterial hypertension since high sodium intake leads to blood pressure increase, stroke, heart attack, and others diseases [1]. On the other hand, potassium is also involved in the control of many human physiological processes, such as arterial pressure and urinary calcium excretion [2]. Therefore monitoring potassium and sodium content in foods is always required by industries and health regulatory agencies.

Diet soft drinks consumption has dramatically increased since the last decade, not only among people that suffer from diabetes, but particularly by those that follow low calories diet in order to control or loose weight. The low calories in diet soft drinks are attained by adding of a combination of artificial sweeteners (cyclamate, saccharine, acesulfame, and aspartame) instead of carbohydrates, such as glucose and sucrose [3]. However some of these sweeteners are usually added as sodium salts (cyclamate and saccharine) what makes diet soft drinks richer in sodium than ordinary soft drinks. On the other hand, diet soft drinks sweetened with acesulfame generally present a higher concentration of potassium than the non-diet version, since acesulfame potassium salts are usually used. Aspartame addition does not contribute to increase neither potassium nor sodium concentration since this peptide is added as a non-salt-type.

Potassium and sodium concentrations are usually determined by atomic absorption or emission techniques. Nevertheless, CE can be an advantageous alternative method for this application because it is a powerful separation technique, mainly for ionic compounds [4-5]. CE is able to 
separate analytes in a short time with good resolution and small sample consumption $(\mathrm{nL})$. The coupling of $\mathrm{CE}$ and $\mathrm{C}^{4} \mathrm{D}$ is more suitable for small ions detection than the usually indirect UV-vis detection method. Although utilization of $\mathrm{C}^{4} \mathrm{D}$ [6-7] is relatively recent it has been applied for determination of several cations, anions [8-9], sugars [10], amines [11] and biomolecules [12] in different kinds of samples. Here we use the CE-C $\mathrm{C}^{4} \mathrm{D}$ for comparing potassium and sodium concentrations in diet and normal soft drink.

\section{Experimental}

\section{Reagents and Solutions}

Analytical grade lactic acid (Lac), L-histidine (His), $\mathrm{KCl}, \mathrm{NaCl}$, and $\mathrm{LiCl}$ were used as received (Fluka, Bucks, Switzerland). Deionized water (Nanopure UV system-Barnstead, Dubuque, IA, USA) was used for solutions preparation. A $20 \mathrm{mmol} \mathrm{L}^{-1} \mathrm{His} / \mathrm{Lac}$ buffer at $\mathrm{pH} 5.0$ was used as background electrolyte (BGE). Stock solutions (100 $\left.\mathrm{mmol} \mathrm{L}^{-1}\right)$ of the $\mathrm{K}^{+}, \mathrm{Na}^{+}$, and $\mathrm{Li}^{+}$were prepared by dissolving the solids in deionized water. Standard solutions were prepared by dilution of the stock solutions as required.

\section{Sample Preparation}

Three different commercial, non-diet and diet, soft drinks were acquired at local market. Two of the samples were guarana-flavoured soft drinks (samples A and B) and another one was a cola soft drink (sample C). The samples were degassed with ultrasonic bath during $10 \mathrm{~min}$ and diluted with deionized water as required. Lithium was introduced $(100 \mu \mathrm{mol} / \mathrm{L}$ in the samples $)$ as internal standard.

\section{CE Separation}

A commercial Waters CE system with adapted $\mathrm{C}^{4} \mathrm{D}$ was used for the analysis. The control and data acquisition was carried out with a computer interfaced to the equipment. A $50 \mathrm{~cm}$ long bare fused-silica capillary with internal diameter of 75 $\mu \mathrm{m}$ was used. The effective separation length was $40 \mathrm{~cm}$, i.e. detector was placed at $10 \mathrm{~cm}$ from the capillary end. The detector was operated at 560 $\mathrm{kHz}$ and $2 \mathrm{~V}$ peak amplitude. The separation voltage was $25 \mathrm{kV}$.

\section{Results and Discussion}

Figure 1 shows electropherograms for separation of $\mathrm{K}^{+}, \mathrm{Na}^{+}$and $\mathrm{Li}^{+}$(internal standard) in a standard solution and samples of non-diet and diet soft drinks. As we can see separations with good peak resolution were attained in less than 2.5 $\min$. 


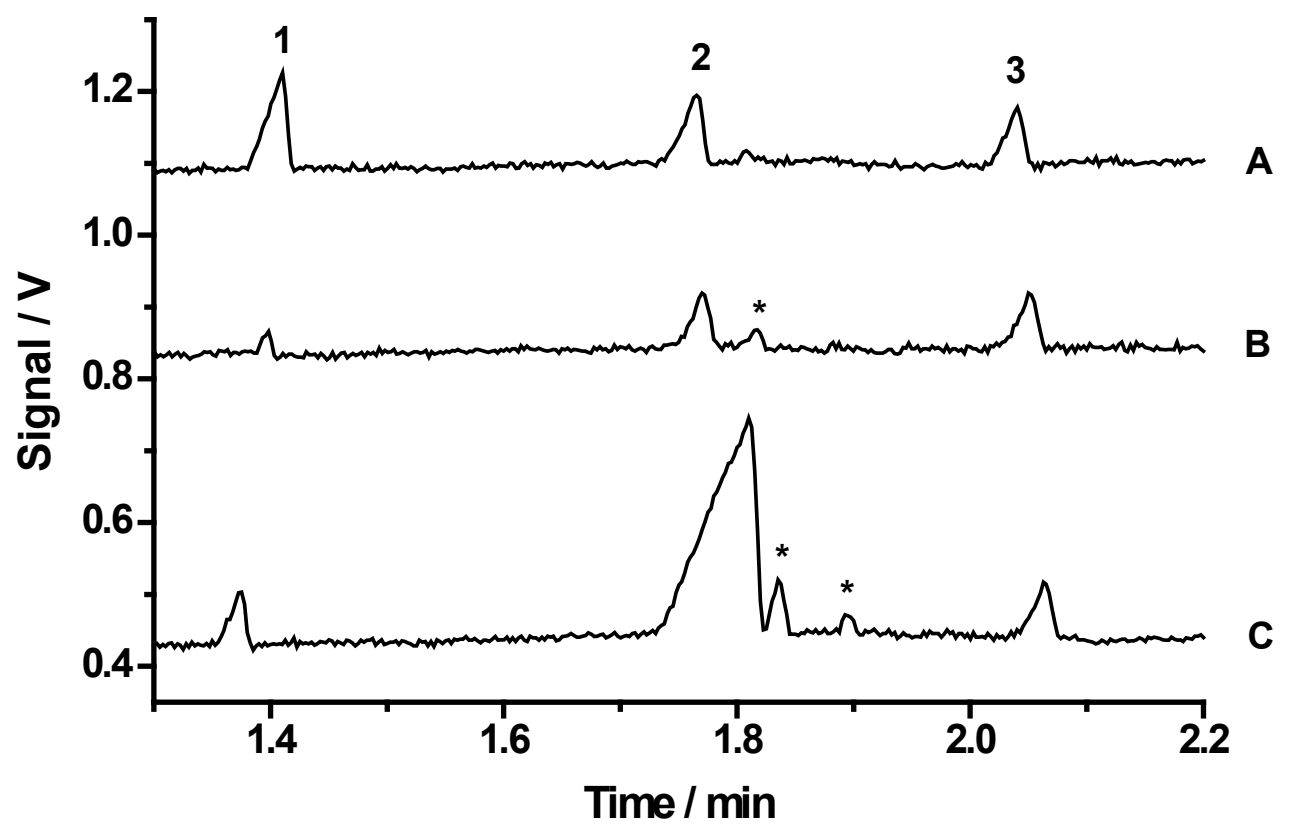

Figure 1. Electropherograms: (A) Standard solution containing $100 \mu \mathrm{mol} \mathrm{L}-1$ of (1) potassium, (2) sodium, and (3) lithium (internal standard); (B) non-diet and (C) diet soft drinks diluted 10-fold with deionized water. Running buffer: $20 \mathrm{mmol} \mathrm{L}^{-1} \mathrm{His} / \mathrm{Lac}$. Separation voltage $25 \mathrm{kV}$; gravity injection at $100 \mathrm{~mm}$ for $30 \mathrm{~s}$; fusedsilica capillary with $75 \mu \mathrm{m}$ inner diameter and $50 \mathrm{~cm}$ long (40 cm effective); (*) not identified peaks.

Table 1 shows the main analytical characteristics of the CE method.

\begin{tabular}{|c|c|c|c|c|c|c|}
\hline Analytes & $\begin{array}{c}\text { LOD }^{\mathrm{a}} \\
\left(\mathrm{mg} \mathrm{L}^{-1}\right)\end{array}$ & $\begin{array}{c}\mathbf{L O D}^{\mathrm{a}} \\
\left(\mathrm{mol} \mathrm{L}^{-1}\right)\end{array}$ & $\begin{array}{c}\mathbf{L O Q}^{\mathrm{b}} \\
\left(\mathrm{mg} \mathrm{L}^{-1}\right)\end{array}$ & $\begin{array}{c}\mathbf{L O Q}^{\mathrm{b}} \\
\left(\mathrm{mol} \mathrm{L}^{-1}\right)\end{array}$ & $\begin{array}{c}\text { Sensitivity } \\
\left(\mathrm{V} \text { min } \text { mol}^{-1} \mathbf{L}\right)\end{array}$ & $\mathbf{R}^{2 \mathrm{c}}$ \\
\hline $\mathrm{K}+$ & 0.13 & $3.26 \times 10-6$ & 0.43 & $1.08 \times 10-5$ & 0.25 & 0.996 \\
\hline $\mathrm{Na}+$ & 0.13 & $5.57 \times 10-6$ & 0.43 & $1.86 \times 10-5$ & 0.19 & 0.993 \\
\hline
\end{tabular}

${ }^{a}$ Limit of Detection for SNR $=3$; b Limit of Quantification for SNR = 10; c Regression coefficient (concentration range: 20 to $100 \mu \mathrm{mol} \mathrm{L}^{-1}$ ) 
Table 2 shows the results for potassium and sodium determination in the soft drink samples.

Table 2. Concentrations of $\mathrm{K}^{+}$and $\mathrm{Na}^{+}$in the evaluated soft drinks

\begin{tabular}{ccc}
\hline Samples & $\mathbf{K}+\left(\mathbf{m g ~ L}^{-1}\right)$ & $\mathbf{N a}+\left(\mathbf{m g ~ L}^{-1}\right)$ \\
\hline A & $24 \pm 4$ & $61 \pm 5$ \\
A $^{*}$ & $15.1 \pm 0.8$ & $181 \pm 24$ \\
B & $22 \pm 2$ & $68 \pm 2$ \\
B $^{*}$ & $9 \pm 1$ & $124 \pm 17$ \\
C & $25 \pm 3$ & $43 \pm 6$ \\
C $^{*}$ & $67 \pm 3$ & $193 \pm 6$ \\
\hline
\end{tabular}

* diet version of the soft drinks

Table 3. Sweeteners present in the evaluated diet soft drinks.

\begin{tabular}{cccc}
\hline Sweeteners & Samples that contain* & Added as potassium salt & Added as sodium salt \\
\hline Saccharine & A, B & no & yes \\
Cyclamate & A, B, C & no & yes \\
Acesulfame & C & yes & no \\
Aspartame & B, C & no & no \\
\hline
\end{tabular}

* Only in diet version

Sodium benzoate, added as conservative, is the main sodium source in non-diet soft drinks. In diet soft drinks sweeteners (cyclamate and saccharine) are added in a sodium-salt-type. For all diet soft drinks studied here higher sodium concentrations were found compared to non-diet version. Therefore, people that need to control sodium intake has to moderate the consumption of diet soft drink, especially those containing cyclamate and saccharine. Although aspartame addition does not provide increase in the sodium concentration the diet version of the samples $\mathrm{B}$ and $\mathrm{C}$ also show higher sodium content than the non-diet version. This can also be explained by the presence of sodium cyclamate and saccharine salts in these samples. Diet soft drinks generally contain a combination of two or more sweeteners in order to improve taste and the sweetening power [3].

For all samples potassium concentrations were found to be lower than the respective sodium ones. The diet version of sample $\mathrm{C}$ presents the highest potassium content (see also figure 2), which is larger than sodium concentration in the non-diet version. This can be understood by considering the manufacturer information that acesulfame is added (see table 3 ) as potassium salt in the diet version of sample $\mathrm{C}$. 


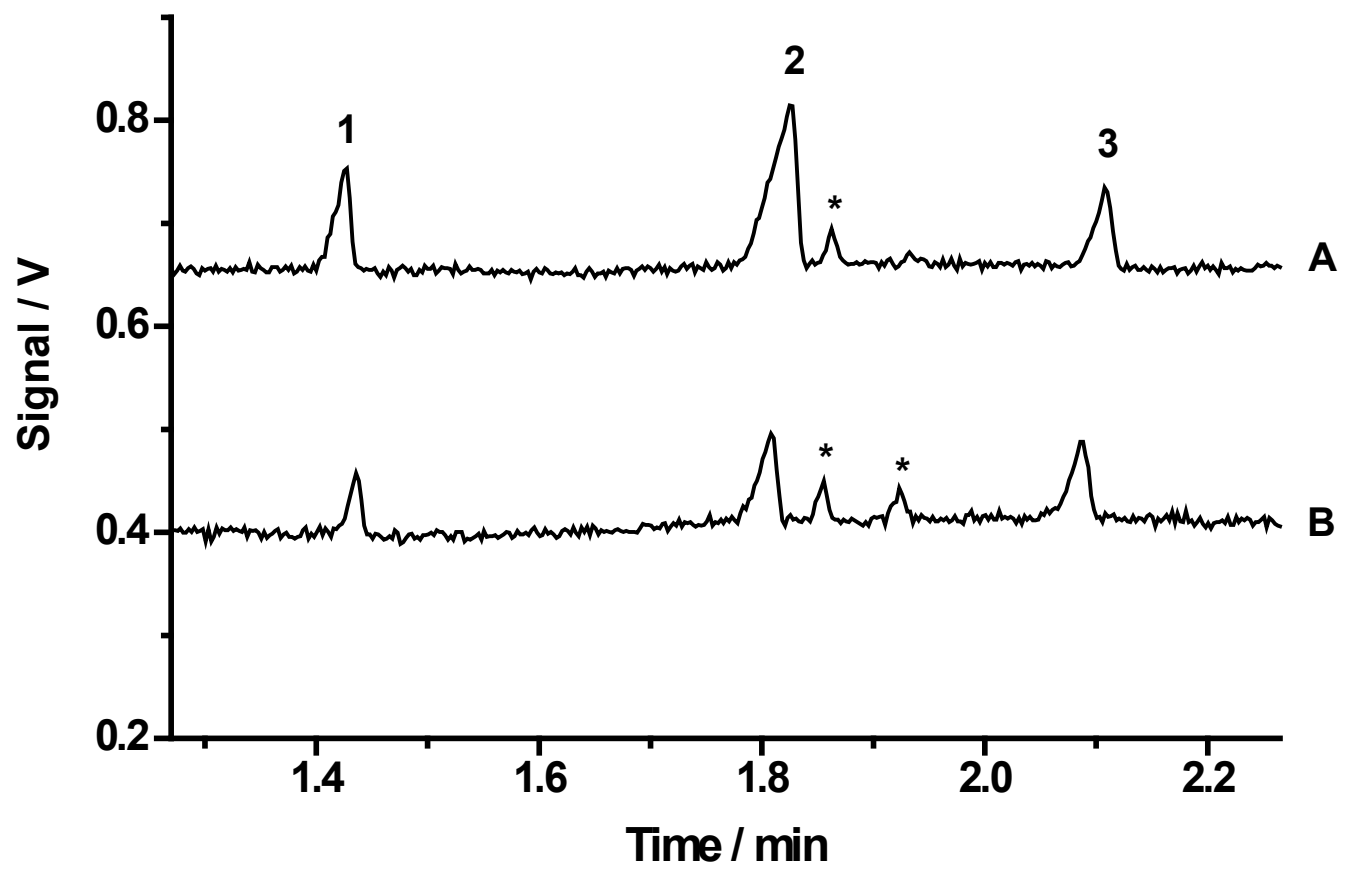

Figure 2. Electropherograms for (A) diet and (B) respective non-diet version of soft drinks diluted 25-fold with deionized water. Running buffer: $20 \mathrm{mmol} \mathrm{L}^{-1} \mathrm{His} / \mathrm{Lac}$. Separation voltage $25 \mathrm{kV}$; gravity injection at $100 \mathrm{~mm}$ for $30 \mathrm{~s}$; fused-silica capillary with $75 \mu \mathrm{m}$ inner diameter and $50 \mathrm{~cm}$ long (40 cm effective); Peaks: (1) potassium, (2) sodium, (3) lithium that was used as internal standard (100 $\left.\mu \mathrm{mol} \mathrm{L}^{-1}\right)$, and (*) not identified peaks.

\section{Conclusions}

Sodium and potassium content in foods have gained a huge importance because depending on the level intake these nutrients can be harmful or beneficent to the human health. CE-C $C^{4} \mathrm{D}$ method used in this work is shown to be a rapid and low sample consumption (nL) analytical technique for potassium and sodium determination in soft drinks. Results obtained for soft drinks consumed in the Brazilian market show that diet version of soft drinks usually contain higher sodium concentration than non-diet version. That information is certainly helpful for people that need to control sodium intake. Hence, the CE-C ${ }^{4} \mathrm{D}$ technique can benefit food industries and health regulatory agencies in monitoring concentrations of potassium, sodium, and other cations not only in soft drinks, but also in many others food products.

\section{Acknowledgments}

This work was supported by the Fundação de Amparo à Pesquisa do Estado de São Paulo (FAFESP), Fundação de Apoio ao Ensino, à Pesquisa e à Extensão da Unicamp (FAEPEXUnicamp), and Conselho Nacional de Desenvolvimento Científico e Tecnológico (CNPq). 


\section{References}

[1] G. A. MacGregor, Am. J. Kidney Dis. 37 (2001) S34.

[2] F. J. He, G. A. MacGregor, Br. Med. J. 323 (2001) 497.

[3] A. Toseto, Master's Dissertation, Universidade Estadual de Ponta Grossa, Brazil, 2005.

[4] M. F. M. Tavares, Quim. Nova 19 (1996) 173.

[5] J. W. Jorgenson, K. D. Lukacs, Anal. Chem. 53 (1981) 1298.

[6] J. A Fracassi da Silva, C. L. Lago, Anal. Chem. 70 (1998) 4339.

[7] J. A. Fracassi da Silva, N. Guzman, C. L. Lago, J. Chromatogr. A 942 (2002) 249.

[8] R. A. A. Munhõz, E. M. Richter, D. P. Jesus, C. L. Lago, L. Angnes, J. Braz. Chem. Soc. 15 (2004) 523.

[9] E. M. Richter, R. A. A. Munhõz, D. P. Jesus, C. L. Lago, Angnes L., J. Braz. Chem. Soc. 16 (2005) 1134.

[10] A. Z. Carvalho, J. A. Fracassi da Silva, C. L. Lago, Electrophoresis 24 (2003) 2138.

[11] X. Y. Gong, P. C. Hauser, Electrophoresis 27 (2006) 468.

[12] E. Samcova, P. Tuma, Electrophoresis 18 (2006) 152. 